\title{
Ophthalmologic Surgical Procedure
}

National Cancer Institute

\section{Source}

National Cancer Institute. Ophthalmologic Surgical Procedure. NCI Thesaurus. Code C15331.

Surgery involving the eyes. 